\title{
A controlled study into the effects of psychoeducation for patients with cognitive disturbances
}

Citation for published version (APA):

Commissaris, K., Verhey, F. R. J., \& Jolles, J. (1996). A controlled study into the effects of psychoeducation for patients with cognitive disturbances. Journal of Neuropsychiatry and Clinical Neurosciences, 8(4), 429-435. https://doi.org/10.1176/jnp.8.4.429

Document status and date:

Published: 01/01/1996

DOI:

10.1176/jnp.8.4.429

Document Version:

Publisher's PDF, also known as Version of record

\section{Please check the document version of this publication:}

- A submitted manuscript is the version of the article upon submission and before peer-review. There can be important differences between the submitted version and the official published version of record.

People interested in the research are advised to contact the author for the final version of the publication, or visit the DOI to the publisher's website.

- The final author version and the galley proof are versions of the publication after peer review.

- The final published version features the final layout of the paper including the volume, issue and page numbers.

Link to publication

\footnotetext{
General rights rights.

- You may freely distribute the URL identifying the publication in the public portal. please follow below link for the End User Agreement:

www.umlib.nl/taverne-license

Take down policy

If you believe that this document breaches copyright please contact us at:

repository@maastrichtuniversity.nl

providing details and we will investigate your claim.
}

Copyright and moral rights for the publications made accessible in the public portal are retained by the authors and/or other copyright owners and it is a condition of accessing publications that users recognise and abide by the legal requirements associated with these

- Users may download and print one copy of any publication from the public portal for the purpose of private study or research.

- You may not further distribute the material or use it for any profit-making activity or commercial gain

If the publication is distributed under the terms of Article $25 \mathrm{fa}$ of the Dutch Copyright Act, indicated by the "Taverne" license above, 


\title{
A Controlled Study Into the Effects of Psychoeducation for Patients With Cognitive Disturbances
}

\author{
Kees Commissaris, Ph.D. \\ Frans R.J. Verhey, M.D., Ph.D. \\ Jellemer Jolles, Ph.D.
}

The therapeutic results of an experimental neuropsychological rehabilitation program, FunctionOriented Guidance (FOG), for patients with mild cognitive disturbances were examined and compared with a regular Function Training (FT) program. FOG is based on thorough evaluation of neuropsychological test results, psychoeducation, and individual counseling. Within the FOG group, but not the FT group, patients' worries decreased and their level of knowledge increased. The results imply that psychoeducation may be of therapeutic value in patients with cognitive disturbances because it improves the way they cope with their handicaps. Contrary to expectations, betweengroup analyses showed few differences between the programs. Nevertheless, it can be concluded that psychoeducation for cognitively disturbed patients can contribute to improving their quality of life. However, further research with more patients is necessary.

(The Journal of Neuropsychiatry and Clinical Neurosciences 1996; 8:429-435)

\begin{abstract}
Deficits of memory and other cognitive functions in the elderly patient may indicate a variety of internal somatic, neurological, or psychiatric disorders. A proportion of these underlying disorders can be treated effectively. ${ }^{1}$ Unfortunately, though, for the majority of these patients no etiological treatment is available. There is a compelling need to develop intervention programs to improve rehabilitation strategies, coping styles, and quality of life. Until now, there have been very few systematic evaluations of treatments aimed at these issues. ${ }^{2}$ Additionally, the few studies on this topic often have had methodological flaws: pretest and posttest sessions or control groups were not included, and participants were usually not assessed neuropsychologically or neuropsychiatrically. ${ }^{3}$

The present study aims at evaluating a therapeutic program, Function-Oriented Guidance (FOG), which was developed by the Maastricht Memory Clinic for elderly patients with mild cognitive deficits. The patients can be regarded as a representative sample of elderly nondemented ambulatory patients with cognitive complaints who visit a neuropsychiatric health care facility.

FOG is a neuropsychological rehabilitation program
\end{abstract}

Received February 27, 1995; revised October 25, 1995; accepted October 31, 1995. From the Department of Neuropsychology, Neuropsychiatry and Psychobiology, University of Limburg, Maastricht, the Netherlands. Address correspondence to Dr. Commissaris, University of Limburg, Department of Neuropsychology, Neuropsychiatry, and Psychobiology, P.O. Box 616, 6200 MD Maastricht, the Netherlands.

Copyright (C) 1996 American Psychiatric Press, Inc. 
that provides psychoeducation by means of individual counseling. Each patient receives detailed information about his or her neuropsychological disturbances and about memory-related factors. The general objective is to increase the patient's insight into his or her cognitive strengths and weaknesses and to train the patient to cope with everyday consequences of these more effectively. ${ }^{4,5}$ Furthermore, the patient is offered practical advice and strategies to aid memory function: Opposed to this approach, a control group was treated by regular Function Training (FT) aimed at the training and retraining of learning and memory abilities; in FT no information was given about personal deficits. In this experimental treatment study the results of FOG and FT are compared in their effects on worries, coping, and knowledge.

The study design was such that the effects of the two programs could be measured independently. The FT group was offered the FOG program after they had completed FT. The main aim of the study was to test the hypothesis that FOG is superior to FT in terms of reducing worries about memory and depression and increasing knowledge and coping abilities. A second aim was to evaluate whether the effect of a combination of the two programs is superior to the effect of FOG or FT alone.

\section{METHODS}

\section{Target Group}

The target group consisted of ambulatory patients of the Maastricht Memory Clinic, which is a health care and research facility for ambulatory neuropsychiatric pa-

TABLE 1. Patient characteristics at baseline

\begin{tabular}{lcc}
\hline Characteristic & $\begin{array}{c}\text { Group } \\
\text { FT + FOG }\end{array}$ & FOG Only \\
\hline Age, years (range) & $59.7(51-75)$ & $60.9(50-75)$ \\
Gender ( $n$, M/F) & $6 / 5$ & $8 / 3$ \\
Education (scale of 1-7; see text) & 4.9 & 4.6 \\
Intelligence Quotient (WAIS) $_{\text {Global Deterioration Scale }}^{21}$ (range) & 116.6 & 112.3 \\
Mini-Mental State Examination $^{8}$ & $2.6(2-3)$ & $2.7(2-3)$ \\
Hamilton Rating Scale for Depression $^{9}$ & 28.9 & 29.3 \\
ABV-Extraversion & 10.3 & 9.6 \\
ABV-Psychic Neuroticism & 4.3 & 3.8 \\
ABV-Somatic Neuroticism & 8.1 & 6.4 \\
ABV-Test Attitude & 7.2 & 7.3 \\
& 3.2 & 4.2
\end{tabular}

Note: Values are means except where otherwise indicated. There were no significant between-group differences. FT $=$ Function Training; FOG = Function-Oriented Guidance; WAIS = Wechsler Adult Intelligence Scale; $\mathrm{ABV}=$ Amsterdam Biographic Questionnaire. ${ }^{20}$ tients. All patients received an extensive neuropsychiatric assessment as described elsewhere. ${ }^{6}$ Included were patients with stable cognitive deficits and chronic memory complaints, irrespective of etiology, that were not severe enough to warrant the diagnosis of dementia. ${ }^{7}$ Patients were included when they had a Mini-Mental State Examination score of at least $28 .{ }^{8}$ Exclusion criteria were delirium; active medical or neurological abnormalities; a DSM-III-R diagnosis of psychosis, substance abuse, or major depression (Hamilton Rating Scale for Depression ${ }^{9}$ score $>18$ ); or the use of psychoactive drugs, with the exception of low and constant dosages of sleeping pills. The symptoms must have been present for at least 1 year.

Twenty-two patients participated in this study. Ten patients met the DSM-III-R criteria for dysthymia. Seven patients had a history of a somatic or neurological disease that was stable at the time of the study (stroke, 2 patients; trauma, 2 patients; von Recklinghausen's disease, Parkinson's disease, and pyramidal tract disease, 1 patient each). Five patients had cognitive deficits of unknown cause. There was no discernible difference between cognitive deficits in patients with a psychiatric disease and in patients with a somatic or neurological disease. Two patients, one in each group, used sleeping pills (lorazepam, $1 \mathrm{mg}$ as needed, and oxazepam, maximum $50 \mathrm{mg}$ as needed). The dosages were low and constant during the intervention and had no effect on the program.

The patients' characteristics are presented in Table 1. Education was measured on a scale from 1 (no education or only a few years of primary school) to 7 (university). Baseline measurements showed no significant difference between the groups.

\section{Research Design}

The patients were matched pairwise in two groups of 11 patients each for etiology ("somatic/neurological" versus "psychiatric"; see above), age, education, and gender. Then subjects of each pair were randomly assigned to the FOG program or to FT. A semi-crossover design was used (Figure 1).

The subjects were assessed by means of questionnaires and tests before and after treatment (at week 0 and week 5). After 5 weeks, the FT group received the FOG program. The FOG group received no further therapy. At week 10, both groups again filled in the questionnaires and took the tests.

\section{Function-Oriented Guidance}

FOG consists of five sessions of 1 hour each. Before session 1 took place, the aim and design of the program were discussed with the patient. 
FIGURE 1. Research design. $X_{1}=$ Function-Oriented Guidance; $X_{2}=$ Function Training; $T_{x}=$ time of measurement.

\begin{tabular}{lccc} 
& Week & Week & Week \\
& 0 & 5 & 10 \\
\cline { 2 - 4 } Experimental group & $T_{1} \frac{X_{1}}{2} T_{2}$ & $T_{3}$ \\
Control group & $T_{1}-X_{2}$ & $T_{2}-X_{1}$ & $T_{3}$
\end{tabular}

Session 1: Information About the Diagnosis: The test results were discussed with the patient and explained in terms of how the patient functioned. A checklist was used to gain information about the individual's daily activities and the extent to which his or her problems affected work, household tasks, and hobbies.

Sessions 2 and 3: Education: The patient received information about human memory, both normal and pathological, about brain functions, and about effective memory strategies to be used in everyday life. The rationale of this intervention is that knowledge about normal forgetfulness is thought to help patients cope with their memory problems and thus decrease the patients' worries. This information is important to enable the patients to understand the advice and to have insight into the possible consequences of their deficits in daily life. In other words, coping and control over deficient memory are the most important aims of FOG. Patients received a brochure on memory function that they were asked to read at home. This brochure was discussed in session 4.

Session 4: Practical Advice: Attention was given to the way the patient coped with his or her cognitive deficits and how this could be improved. Patients were given general advice much like that given to all brain-injured persons. For instance, they were advised about stabilization of stimuli from the environment and communication in concrete, short sentences. In addition, each was given specific advice related to his or her cognitive profile or specific problems. Patients were also advised to use mnemonic strategies.

Session 5: Evaluation: The goals and outcomes of the treatment were discussed with the patient. The posttherapy evaluation tests were also given in session 5.

\section{Function Training}

The Function Training in this study is a regular program for patients with memory and other cognitive deficits. FT has been used before as a control program in studies investigating the effects of memory rehabilitation and has also been called "pseudorehabilitation" or "drill and practice. $^{\prime 2}$ The use of FT as a control program enables the investigator to control for possible improvements due to nonspecific factors, such as attention received and amount of exercise. FT aims at practicing and retraining learning and memory abilities. Attention is paid to different aspects of memory, such as working memory and short-term memory. Individuals are allowed to follow their personal styles of learning but do not receive specific information about how memory works or about coping styles, strategies, or memory aids to be used in daily practice. The program consists of five sessions of 1 hour each. In contrast to FOG, FT provides no information about the individuals' disturbed and normal cognitive functions.

Measures of Evaluation

Questionnaire: "Knowledge About Memory"3 (KAM): This questionnaire with 34 items was based on the most important subjects covered by the brochure, namely: 1) general information about memory, 2) information about changes in the working of memory with age and causes of memory problems, and 3) information about coping with memory problems in daily life. The patients could give three answers: "right," "wrong," or "don't know." Examples of questions are: "A memory complaint is always an indication of a memory deficit" (wrong) and "Stress and tension may have a negative influence on the working of people's memory" (right). A scale of 19 items with sufficient discriminative power was used to evaluate knowledge (Cronbach's alpha= $0.70)$. The number of correct answers $(0-19)$ was taken as a measure of knowledge.

Neuropsychological Tests: The following neuropsychological tests were used. The Auditory Verbal Learning Test (AVLT) is a Dutch version of the Rey AVLT. ${ }^{10,11}$ This test consists of one list of 15 monosyllabic and concrete Dutch nouns, which are presented in five trials by means of a tape recorder. Each trial ends with a free recall of the words. Three scores were used: the total number of correct answers after five presentations, measuring learning ability (Immediate Recall); the total number of correct answers 20 minutes after the fifth presentation, measuring consolidation in long-term memory (Delayed Recall); and the recognition of the 15 words that were presented previously among 15 new words (Delayed Recognition). Parallel versions of the AVLT were used. The Stroop Color Word Interference Test ${ }^{12}$ measures the ability to shift between two response tendencies (color and names). Stroop I and II measure the speed at which color words are read and colored 
spots are named, respectively, and Stroop III measures susceptibility to interference. The standard version was used with 100 words on each card. The Trail Making Test $^{13}$ (TMT) and the Concept Shifting Task ${ }^{14}$ (CST) were used to measure the speed of shifting concepts. This measurement was made operational by alternate marking of numbers and letters in an ascending order. The Symbol Digit Modalities Test ${ }^{15}$ (SDMT) was used to measure complex information processing under time pressure (reading and writing tasks).

Other Assessment Scales: The questionnaire of the Memory Assessment Clinics ${ }^{16}$ (MAC) was used to measure subjective memory problems. These questions give insight into how well people perform in daily situations in which they have to use their memory (Ability)-for example, remembering names, faces, or telephone numbers-and how often they forget certain things in daily life-for example, losing the thread of a conversation or not recognizing people who recognize them (Occurrence). Both the MAC-IV (Impression of the Patient) and the MAC-III (Impression of the Proxy) were used. Patients' worries about their own memory were measured on a 5-point likert scale (item of MAC-IV). The Zung depression $s$ ale ${ }^{17}$ was used to measure depressive symptoms and feelings in general; the Spielberger State-Trait Anxiety Inventory ${ }^{18}$ (STAI-State) was used to measure anxiety; and the Utrecht Coping List $^{19}$ (UCL) was used to measure coping behavior. In contrast to the Zung, the Depressive Thoughts subscale of the UCL measures internal attributions and how the patient copes with depressive thoughts in daily life-for example, by sharing these thoughts with significant others. The UCL consists of seven subscales. The Zung, STAI, and UCL tests were used at baseline, at week 5 , and at week 10. The Amsterdam Biographic Questionnaire ${ }^{20}$ (ABV) was used at baseline.

\section{Statistical Analyses}

To examine the effects of both programs, we compared the scores at week 5 and week 0 by using repeated-measures multivariate analysis of variance (MANOVA). Variables with different baseline measurements (three subscales of the UCL) were tested with multivariate analysis of covariance (MANCOVA) with baseline measurements as covariate. Probabilities greater than 0.05 were considered nonsignificant.

\section{RESULTS}

Baseline Measures

At baseline there were no differences between the two groups on main variables (Table 1). However, three items of the UCL were different. The FT group scored higher on palliative habits $(t=3.2 ; P<0.01)$, whereas the FOG group was better at solving problems $(t=2.6$; $P<0.05)$ and also showed a less hesitant attitude $(t=$ $4.1 ; P<0.01)$. All variables showed a normal distribution. The partners of patients in both groups were less worried about the patient's memory than the patient was $(t=4.4 ; P<0.001)$.

Both groups had average KAM scores between 10.5 and 11.0 before the program (range 6-15). All patients were worried to some extent about their memory, but there was no correlation between their worries and their KAM scores, nor between worries and age. The older patients had lower KAM scores $(r=-0.62 ; P<0.01)$.

The performance of several neuropsychological tests was negatively correlated with people's worries about their memory $(P<0.05)$. These tests were the Stroop III $(r=-0.47)$, the Immediate Recall of the AVLT $(r=-$ $0.43)$, and Delayed Recall $(r=-0.50)$. Patients with few worries about their memory performed these tests better than patients who were more worried about their memory.

\section{Evaluation of Outcome Measures}

Table 2 shows that after the program the patients of the FOG group had significantly higher scores on the KAM than the patients of the FT group $(F=5.4, \mathrm{df}=1, P<$ 0.05 ). The patients of the FOG group also sought more social support, a manifestation of a better way of coping $(F=5.8, \mathrm{df}=1, P<0.05)$. This improvement was independent of baseline differences between the two groups on the UCL variables Active Problem Solving and Showing a Hesitant Attitude. Both findings are in accordance with our hypotheses.

No other significant differences were found between the two groups at week 5 . This result was not according to our expectations. We had expected the patients of the FOG group to become less worried and less depressed than the patients of the FT ornun Mnrenver. hecause FT wao ai-... -1 
However, this effect was not found at week 10 , nor did the FT group become less depressed after they had followed FOG. The FOG group also performed better on the Stroop II, an improvement that was still present at week 10 (Table 3).

Except for a decrease in worrying about memory function, the patients of the FT group did not score better on any of the other assessment scales than before therapy. As expected, patients of the FT group performed significantly better on several neuropsychological parameters. They made more correct answers in the Immediate Recall test of the AVLT $(F=4.5, \mathrm{df}=1, P<$ $0.05)$ and in the delayed recall test $(F=3.9, \mathrm{df}=1, P<$

TABLE 2. Results of both programs at week 5 in comparison with week 0

\begin{tabular}{|c|c|c|c|c|}
\hline & \multicolumn{2}{|c|}{ FT } & \multicolumn{2}{|c|}{ FOG } \\
\hline & Week 0 & Week 5 & Week 0 & Week 5 \\
\hline \multicolumn{5}{|l|}{ Neuropsychological variables } \\
\hline \multicolumn{5}{|l|}{ Auditory Verbal Learning Test } \\
\hline Immediate Recall & 37.7 & $43.8^{\mathrm{d}}$ & 34.7 & 39.0 \\
\hline Delayed Recall & 6.8 & $8.6^{\mathrm{d}}$ & 5.6 & 6.5 \\
\hline Delayed Recognition & 13.0 & 13.4 & 12.4 & 13.6 \\
\hline \multicolumn{5}{|l|}{ Stroop Test } \\
\hline Stroop I & 56.2 & 50.9 & 49.7 & 50.6 \\
\hline Stroop If & 74.5 & 61.3 & 66.9 & $58.7^{\circ}$ \\
\hline Stroop III & 127.3 & $110.3^{c}$ & 131.6 & 128.5 \\
\hline Stroop Interference & 52.7 & 49.0 & 65.7 & 69.7 \\
\hline Trail Making Test & 91.5 & $810^{\circ}$ & 773 & 747 \\
\hline Concept Shifting Task & 41.7 & $33.6^{d}$ & 28.6 & 23.7. \\
\hline SDMT (Reading correct) & 453 & $48.4^{d}$ & 41.9 & 43.4 \\
\hline SDMT (Writing correct) & 39.4 & 39.4 & 40.8 & 38.8 \\
\hline Knowledge (\# correct items) & 10.9 & 11.4 & 10.6 & $14.6^{\mathrm{b}}$ \\
\hline \multirow{2}{*}{\multicolumn{5}{|c|}{$\begin{array}{l}\text { Other assessment scales } \\
\text { MAC Questionnaire }\end{array}$}} \\
\hline & & & & \\
\hline MAC-III (Occurrence) & 70.2 & 75.1 & 72.0 & 74.7 \\
\hline MAC-III (Ability) & 62.1 & 64.1 & 59.4 & 60.1 \\
\hline MAC-IV (Occurrence) & 83.6 & 77.6 & 76.9 & 73.2 \\
\hline MAC-IV (Ability) & 67.8 & 63.5 & 62.7 & 60.9 \\
\hline Worries About Memory & 4.1 & $3.5^{\mathrm{d}}$ & 4.4 & $3.6^{\mathrm{d}}$ \\
\hline STAI (State-anxiety) & 40.3 & 40.4 & 41.1 & 39.6 \\
\hline Zung (Depression) & 45.5 & 43.1 & 40.4 & $36.6^{\mathrm{d}}$ \\
\hline \multicolumn{5}{|l|}{ Utrecht Coping List } \\
\hline Active Problem Solving & 14.8 & 15.5 & 20.6 & 19.2 \\
\hline Palliative Habits & 18.3 & 17.8 & 13.0 & 13.0 \\
\hline Showing a Hesitant Attitude & 18.4 & 17.8 & 13.9 & 12.3 \\
\hline Seeking Social Support & 12.6 & 11.5 & 10.2 & $12.6^{\mathrm{b}}$ \\
\hline Depressive Thoughts & 13.4 & 13.1 & 10.2 & 10.4 \\
\hline Expressing Emotions & 4.8 & 4.8 & 5.9 & 6.1 \\
\hline Reassuring Oneself & 16.5 & 15.1 & 18.2 & 17.1 \\
\hline \multicolumn{5}{|c|}{$\begin{array}{l}\text { Note: } \quad \text { FT }=\text { Function Training; FOG }=\text { Function-Oriented } \\
\text { Guidance; SDMT = Symbol Digit Modalities Test; MAC = Memory } \\
\text { Assessment Clinics; STAI = State-Trait Anxiety Inventory. } \\
\text { asignificant difference between groups; } P<0.01 \text {. } \\
\text { bSignificant difference between'groups; } P<0.05 . \\
\text { 'Significant difference within groups; } P<0.01 \text {. } \\
\text { dSignificant difference within groups; } P<0.05 . \\
\end{array}$} \\
\hline
\end{tabular}

$0.05)$ than before therapy. They also performed better on the Stroop III $(F=7.9, \mathrm{df}=1, P<0.01)$, the TMT ( $F$ $=7.8, \mathrm{df}=1, P<0.01)$, the CST $(F=4.2, \mathrm{df}=1, P<$ $0.05)$, and the SDMT reading task $(F=3.8, \mathrm{df}=1, P<$ $0.05)$. This progress was not correlated with the decrease in worries, but was the result of retraining and practicing memory abilities.

We then investigated whether a combination of the two programs was more effective than FOG alone. All patients of the FT group received FOG after they had completed FT. The effects were again measured with MANOVA (repeated measures). The results of the FT + FOG group at week 10 were compared with the results

TABLE 3. Results of both programs at week 10 in comparison with week 0

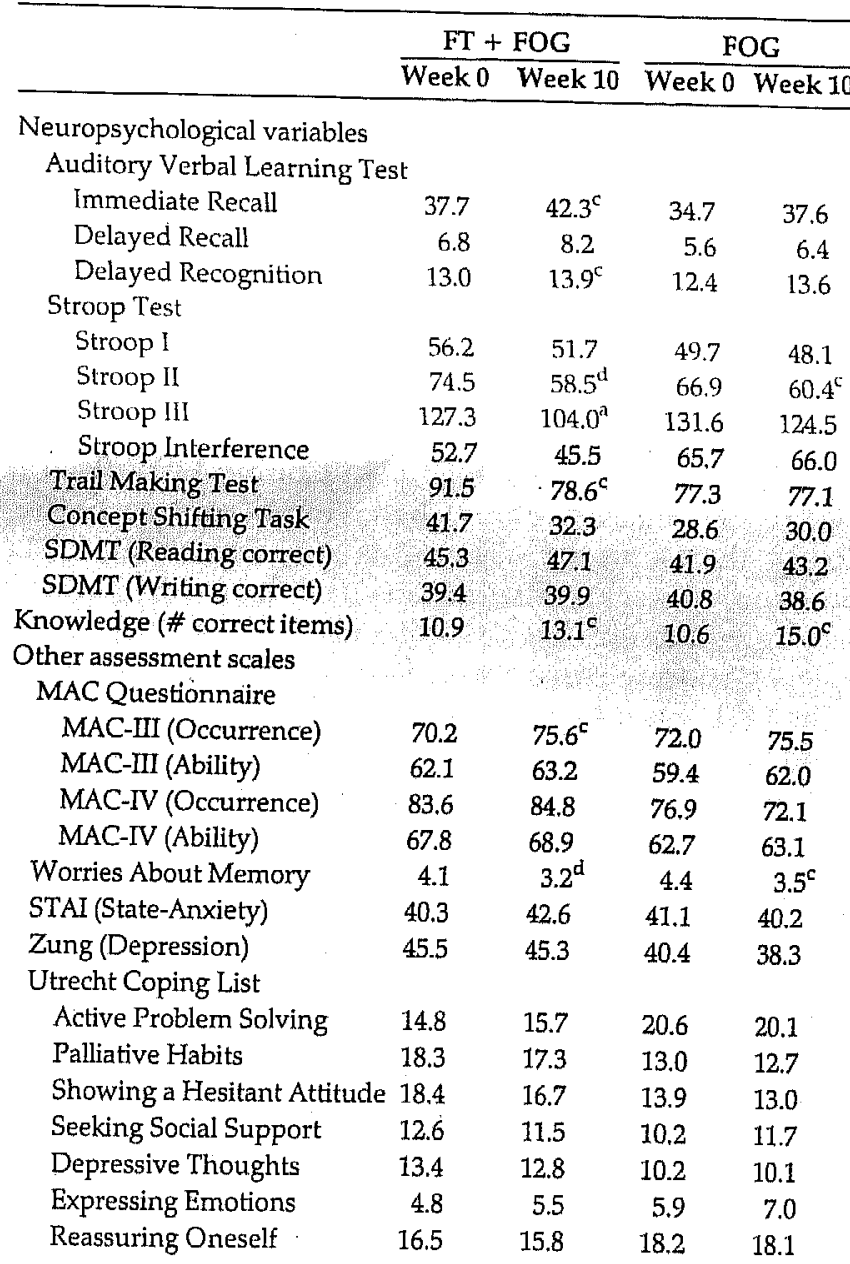

Note: $\mathrm{FT}=$ Function Training; FOG $=$ Function-Oriented Guidance; SDMT $=$ Symbol Digit Modalities Test; MAC = Memory Assessment Clinics; STAI = State-Trait Anxiety Inventory.

aSignificant difference between groups; $P<0.05$.

'Significant difference within groups; $P<0.01$.

${ }^{\mathrm{d}}$ Significant difference within groups; $P<0.05$. 
of the FOG group at week 5. There was only a slight difference between the groups: the patients of the FT + FOG group performed considerably better than their FOG counterparts on the Stroop III $(F=4.0, \mathrm{df}=1, P<$ 0.05). We had expected that patients of the FT + FOG group would perform better on more tests. The initial differences in level of knowledge and the UCL variable Seeking Social Support were no longer present at week 10 . We then tested whether changes had occurred within both groups with time (Table 3 ).

The increased knowledge of the patients of the FOG group at week 5 was still measurable at week 10 . The knowledge of the patients of the FT group also increased after they had followed FOG. The patients of both groups were slightly less worried about memory than previously. However, there was no significant correlation between patients' worries about their memory and their KAM scores. At week 10, the FT + FOG group scored better on the MAC-IV (Occurrence) than the FOG-only group, indicating that they considered themselves less forgetful. The initial improvement of this group on the Immediate Recall and the TMT at week 5 was still present at week 10. Despite a further improvement in the CST, the progress at week 10 was no longer significant. At week 10 the patients of the FT + FOG group performed better on the delayed recognition test $(F=4.8, \mathrm{df}=1, P<0.05)$ and the Stroop $\Pi(F=3.5, \mathrm{df}$ $=1, P<0.05)$ than they did at week 5 . Performance on the other tests did not change.

\section{DISCUSSION}

The main findings of this study can be summarized as follows: 1) FOG resulted in more knowledge about cognitive functioning than $\mathrm{FT}$, and this effect was still measurable at week 10; and 2) a combination of the two programs was not more effective than the FOG program alone. The increased level of knowledge of the FOG group was in line with our expectations, given that FOG involved education in session 2 and practical advice in session 4 . The results show that this patient group is very well able to store and recall new information and to use it in daily life.

After the program the patients in both groups were significantly less worried about their memory, but the patients in the FOG group sought more social support than those in the FT group, indicating a better coping strategy with memory and cognitive problems in daily life. This finding is relevant, although we had expected progress on more aspects of coping in the experimental group. Although patients in the FOG group also showed fewer symptoms of depression after the pro- gram, this effect was not consistently found in the evaluation at week 10, or within the FT group after they received FOG. These findings indicate that FOG is not primarily therapeutic with regard to depression.

Within-group analyses showed that the patients of the FOG group had improved their performance on only one neuropsychological test. The Function Training group performed significantly better on six neuropsychological parameters after FT. This result is according to our expectations and can be regarded as a direct effect of the retraining that was the essence of the FT program.

A weakness of the present study is the relatively large number of dependent variables that were tested in relation to the small size of the sample (Tables 2 and 3 ). Because of this, there is a possibility that differences that were found occurred by chance. However, because of the exploratory character of the study, we chose not to use the Bonferroni procedure that protects against spurious significance from multiple comparisons.

Why favor FOG over FT when both programs lead to a reduction of patients' worries about their memory? The primary reason is that when FOG is used this effect may last longer. A possible explanation for decreased worries in the FT group is that patients benefited from receiving the undivided attention of a specialist. In addition, they may have experienced some form of control over their memory performance because of the experience in performing memory and learning tasks. However, because the attention given to the patients in the FT group is nonspecific and because they did not have increased knowledge about memory processes, it is questionable whether they will remain reassured in the long term. In the FOG group, however, people were informed about their cognitive functioning, they were taught to cope with memory problems in daily life, and they received information about how memory works and about the optimal conditions for using memory adequately. The important finding in this study is that it is indeed possible to give patients with cognitive complaints a psychoeducation that leads to more knowledge that can still be measured several weeks later. Thus, good memory consolidation must have taken place, which is a prerequisite for use of this information in daily practice. Furthermore, the decreased worries in the FOG group are significantly correlated with an increased level of knowledge $(r=0.70)$. Therefore, this group is more likely to remain reassured in the long term. Suggestive evidence for this is the finding that the FOG group was still less worried after 5 weeks of no treatment (week 10).

A follow-up study in 40 patients suffering from cognitive complaints is presently being performed in our 
clinic to elaborate on the findings from the present study and to evaluate the long-term effects of both programs.

In summary, our results indicate that psychoeducation by means of FOG could have a beneficial effect for people with mild objective cognitive deficits. The results also indicate that individual counseling, backed up with a brochure, can be useful for this category of patients.

The authors are grateful to Ellen Reyersen van Buuren, neuropsychologist, for her contribution to this research project.

\section{References}

1. Verhey FRJ: Dementia, depression and forgetfulness: clinical studies of the early diagnosis and the differential diagnosis of dementia. Doctoral dissertation. Maastricht, the Netherlands, University Press Maastricht, 1993

2. Berg If, Koning-Haanstra M, Deelman BG: Long-term effects of memory-rehabilitation: a controlled study. Neuropsychological Rehabilitation 1991; 1:97-111

3. Commissaris CJAM: Voorlichting over geheugenproblemen en dementie, proefschrift [Education about memory problems and dementia]. Doctoral dissertation. University of Limburg, Maastricht, the Netherlands, 1993

4. Reyersen van Buuren EJ, Jolles J: Function-Oriented Guidance as a form of neuropsychological rehabilitation for memory disturbed patients, in Rehabilitation of the Brain Injured: A Neuropsychological Perspective, edited by Vakil E, Hoofien D, Groswasser ZL. London, Freund, 1990, pp 87-103

5. Miller E: Recovery and Management of Neuropsychological Impairments. New York, Wiley, 1984

6. Verhey FRJ, Jolles J, Ponds RWHM, et al: Diagnosing dementia: a comparison between a monodisciplinary and a multidisciplinary approach. J Neuropsychiatry Clin Neurosci 1993; 5:78-85

7. American Psychiatric Association: Diagnostic and Statistical Manual of Mental Disorders, 3rd edition, revised. Washington, DC, American Psychiatric Association, 1987

8. Folstein MF, Folstein SE, McHugh PR: "Mini-Mental State": a practical method for grading the cognitive state of patients for the clinician. J Psychiatr Res 1975; 12:189-198

9. Hamilton M: A rating scale for depression. J Neurol Neurosurg Psychiatry 1960; 23:56-62
10. Brand $N$, Jolles J: Learning and retrieval rate of words presented auditorily and visually. J Gen Psychol 1985; 17:145-153

11. Lezak MD: Neuropsychological Assessment, 2nd edition. Oxford, Oxford University Press, 1983

12. Stroop JR: Studies of interference in serial verbal reactions. J Exp Psychol 1935; 18:643-662

13. Armitage SG: An analysis of certain psychological tests used for the evaluation of brain injury. Psychological Monographs 1946; 60:whole no 277

14. Houx PJ: Cognitive aging and health-related factors. Doctoral dissertation. University of Limburg, Maastricht, the Netherlands, 1991

15. Smith A: Symbol Digit Modalities Test. Los Angeles, Western Psychological Services, 1973

16. Crook TH III, Larrabee GJ: A self-rating scale for evaluating memory in everyday life. Psychol Aging 1990; 5:48-57

17. Zung WK: A self-rating depression scale. Arch Gen Psychiatry 1964; $17: 845-848$

18. Ploeg HM van der, Defares PB, Spielberger CD: Handleiding bij de zelf-beoordelingsvragenlijst [Manual on a self-rating questionnaire]. Lisse, the Netherlands, Swets and Zeitlinger, 1981

19. Schreurs PJG, Willige $G$ van de, Tellegen B, et al: De Utrechtse Coping Lijst: UCL [The Utrecht Coping List]. Lisse, the Netherlands, Swets and Zeitlinger, 1987

20. Wilde GJS: Neurotische labiliteit gemeten volgens de vragenlijstmethode [Neurotic lability measured by a questionnaire method]. Amsterdam, Van Rossen, 1970

21. Reisberg B, Ferris S, de Leon M, et al: The Global Deterioration Scale for assessment of primary degenerative dementia. Am J Psychiatry 1982; 139:1136-1139 